\title{
Grupos de Idosos: Atuação da Psicogerontologia no Enfoque Preventivo
}

\author{
Groups of Elderly: \\ Action of Psicogerontology in the Preventive Approach
}

Grupos de Ancianos:

Actuación de la Psicogerontología en el Enfoque Preventivo

Olga Nazaré

Pantoja de Morais

Secretaria Municipal de

Saúde - Pará
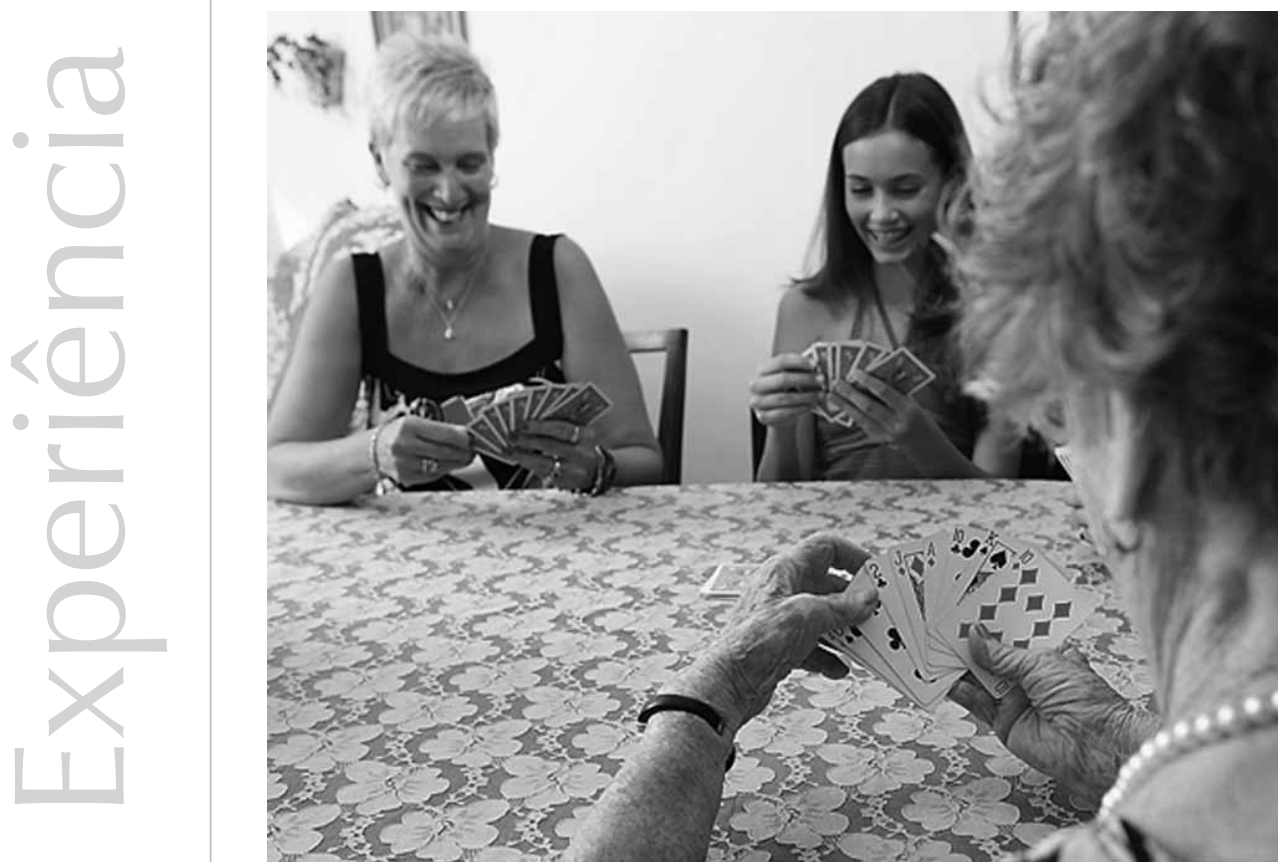
Resumo: Este artigo descreve estratégias de enfrentamento saudável do processo de envelhecimento através da intervenção grupal do setor de psicologia de um centro de referência à saúde do idoso. São discutidos os aspectos psicológicos envolvidos no envelhecimento, as limitações e dificuldades dessa fase bem como as possibilidades saudáveis de enfrentamento desse processo. A atuação com grupos é uma importante contribuição na formação de uma rede de suporte psicossocial. Os grupos desenvolvidos foram: Cuidando do Cuidador, que proporcionou momentos de reflexão sobre o "cuidar" a familiares e/ou idosos que exercem a função de cuidadores; o grupo Exercitando o Corpo e a Mente, que estimulou os idosos à descoberta de práticas corporais e estímulos mentais saudáveis em seu cotidiano, e Cuidando da Saúde com Alegria, que visou à conscientização do autocuidado nos idosos participantes, através da descoberta de atividades prazerosas em seu dia a dia. Os resultados alcançados mostraram que os idosos atendidos nesses grupos passaram a perceber a necessidade de responsabilizarem-se pela própria saúde como prioridade em suas vidas. A intervenção do psicólogo como agente facilitador do processo grupal mostrou relevante importância no atendimento com idosos, visto sua notável contribuição na aquisição e/ou manutenção de uma velhice saudável.

Palavras-chave: Processo de envelhecimento. Grupo. Velhice saudável. Prevenção.

\begin{abstract}
This article describes strategies for confronting the process of healthy ageing through the intervention of the industry group psychology of a reference center for the elderly's health. The psychological aspects involved in ageing, the limitations and difficulties of this period, and the possibilities of healthy confrontation of this process are discussed. The activities with groups are an important contribution in forming a psychosocial network support. The following groups were developed: Caring for the Carer, which provided moments of reflection on the "care" to relatives and/or elderly people engaged in the task of carers, the group Exercising Body and Mind, that encouraged the elderly to discover the practice of healthy physical and mental stimuli in their daily lives, and Caring for Health with Joy, aimed at the awareness of self-care in the elderly participants through the discovery of pleasant activities in their daily life. The results showed that the elderly people who attended these groups began to understand that the need to be responsible for their own health was a priority in their lives. The intervention of the psychologist as a facilitator of the process group showed relevant importance in the elderly care, due to his/her remarkable contribution in the acquisition and/or maintenance of healthy old age.
\end{abstract}

Keywords: Aging process. Group. Old age. Prevention.

Resumen: Este artículo describe estrategias de enfrentamiento saludable del proceso de envejecimiento a través de la intervención grupal del sector de psicología de un centro de referencia con la salud del anciano. Son discutidos los aspectos psicológicos involucrados en el envejecimiento, las limitaciones y dificultades de esa fase así como las posibilidades saludables de enfrentamiento de ese proceso. La actuación con grupos es una importante contribución en la formación de una red de soporte psicosocial. Los grupos desarrollados fueron: Cuidando del Cuidador, que proporcionó momentos de ponderación sobre el "cuidar" a familiares y/o ancianos que ejercen la función de cuidadores; el grupo Ejercitando el Cuerpo y la Mente, que estimuló los ancianos al hallazgo de prácticas corporales y estímulos mentales saludables en su cotidiano, y Cuidando de la Salud con Alegría, que pretendió la concienciación del auto-cuidado en los ancianos participantes, a través del hallazgo de actividades placenteras en su día a día. Los resultados alcanzados mostraron que los ancianos atendidos en esos grupos pasaron a percibir la necesidad de que se responsabilicen por la propia salud como prioridad en sus vidas. La intervención del psicólogo como agente facilitador del proceso grupal mostró relevante importancia en el servicio con ancianos, visto su notable contribución en la adquisición y/o mantenimiento de una vejez saludable.

Palabras clave: Proceso de envejecimiento. Grupo. Vejez saludable. Prevención.

Atualmente, no Brasil e no mundo, tem aumentado, alarmantemente, o número de pessoas idosas. Em nosso país, esse número tem obtido uma rápida elevação, passando de $4,2 \%$, em 1950 , para $7,1 \%$, atualmente (Papaléo Netto, 2005, p. 3). O Brasil, portanto, deixa de ser considerado um país de jovens. Dois principais fatores justificam esse aumento, sendo o primeiro a redução da taxa de natalidade, pois as mulheres podem optar por terem poucos filhos, vista a eficácia dos métodos contraceptivos presentes no mercado, e o segundo, a redução da morbidez e da mortalidade, uma vez que as descobertas tecnológicas atuais têm contribuído para maior controle das 
patologias antes consideradas letais, com a prevenção e melhores esclarecimentos quanto à saúde, que vêm sendo determinantes nessa diminuição (Zimerman, 2000).

A velhice vem ganhando uma nova visão, na qual passou a ser percebida como uma fase com muitas possibilidades de aprendizagem e conhecimento. A busca de novas estratégias para o enfrentamento do processo de envelhecimento tem se tornado o motivo da minha escolha por estudar e atuar nessa área. O Centro de Atenção à Saúde do Idoso é uma unidade de referência ao atendimento dos idosos, sendo a equipe formada por profissionais que realizam um trabalho multidisciplinar.

Inicialmente, o atendimento psicoterápico e de apoio individualizado foram as estratégias usadas em um primeiro contato com os idosos, no qual aprendi que a escuta e a disposição para tal eram o segredo para compreendêlos e ser merecedora de sua confiança, pois, muitas vezes, encontravam-se fragilizados com os problemas do cotidiano. As atividades com grupos de idosos também foram utilizadas como recurso de atendimento, sendo formados vários grupos a partir da demanda apresentada pelos idosos. Os grupos desenvolvidos foram: grupo Cuidando do Cuidador, grupo Cuidando da Saúde com Alegria e grupo Exercitando o Corpo e a Mente, tendo todos como principal objetivo a prevenção e a promoção da saúde.

Essa experiência, que será relatada ao longo deste artigo, tem o objetivo de contribuir e fomentar nos profissionais de saúde o interesse e a disposição de valorizar, com mais respeito e dedicação, essa parcela da população que cresce em ritmo acelerado em nosso país e que, até então, vinha tendo um tratamento pouco "cuidadoso" por parte de grande segmento da sociedade e das autoridades governamentais.

\section{A interface da Psicologia no processo do envelhecimento}

Na literatura atual, inúmeras definições do processo de envelhecimento são encontradas, entretanto, deu-se preferência à definição de Neri (2001), visto que engloba todos os aspectos relevantes, sendo conceituado

...como uma seqüência de mudanças naturais previsíveis, com repercussões orgânicas e psicossociais que ocorrem através do tempo. Entretanto, essa experiência se dá de forma heterogênea, já que pode ocorrer de modo diferente para indivíduos que vivem em contextos históricos, sociais e culturais distintos. (p. 28)

No processo de envelhecimento, estão envolvidas, portanto, dimensões psicológicas, influenciadas por fatores que contribuem para a percepção de aspectos subjetivos, que irão determinar o enfrentamento e a qualidade de vida do idoso. O envelhecimento é marcado por peculiaridades de cada indivíduo, tornando-se necessário levar em consideração a capacidade de manutenção funcional ou disfuncional do idoso para realizar suas atividades cotidianas, já que a maneira de enfrentar o processo desencadeado pelo envelhecimento contribui para a qualidade de vida na velhice.

As dificuldades e limitações desencadeadas nesse processo estão diretamente ligadas à forma como o indivíduo percebe o seu envelhecimento, enquanto ser que comanda a sua existência, entrelaçada por valores préconcebidos durante todo o seu processo de desenvolvimento. Aqui, considera-se essa percepção como a auto-atribuição dos traços característicos da velhice através da manifestação subjetiva diante das alterações sofridas, em nível somático e funcional. Em conseqüência, existem vários fatores que contribuem para o desenvolvimento de conflitos e crises comuns a essa fase da vida, que, segundo Stuart-Hamilton (2002, pp. 134-140), são: 
Zimerman (2000) afirma que:

As pessoas mais saudáveis e mais otimistas têm condições de se adaptarem às transformações trazidas pelo envelhecimento. Elas estão mais propensas a verem a velhice como um tempo de experiências acumuladas, de maturidade, de liberdade para assumir novas ocupações e, até mesmo, de liberação de certas responsabilidades. (p. 25)
- Surgimento de doenças crônicas que deterioram a saúde e estão freqüentemente acometendo os idosos;

- Modificações orgânicas x auto-imagem;

- Viuvez, morte de amigos e parentes;

- Ausência de papéis sociais favoráveis;

- Dificuldades financeiras (aposentadoria).

Todos esses fatores contribuem para que o idoso tenha sua auto-estima afetada, o que gera muitos conflitos e crises na busca de uma identidade diante das muitas mudanças que vivencia. Para enfrentar todas essas mudanças, o idoso necessitará recorrer aos recursos internos (formas pessoais de enfrentamento) e externos que estiverem disponíveis.

Para Jung, o envelhecimento suscita a abertura de novas possibilidades, em que considera o balanço entre limites e perdas como o aspecto psicológico básico do processo de envelhecer (como citado por Freitas et al., 2002). Nessas circunstâncias, o idoso pode sofrer uma paralisação ou bloqueio emocional em relação às respostas que emite aos estímulos externos, com o desencadeamento de doenças como a depressão. "Como a vida se dá pela tensão dos contrários, o processo de envelhecer, com suas metamorfoses, nos apresenta ganhos e perdas" (Monteiro, 2002, p. 13). Existe a possibilidade de o idoso conseguir adaptar-se com maior facilidade a todo esse processo, reagindo de maneira positiva às mudanças ocorridas. Neri (2001) salienta algumas alternativas possíveis para esse enfrentamento:

- Apoio e suporte familiar são considerados de fundamental importância para que o idoso possa preservar sentimentos de reconhecimento e pertencimento junto às pessoas que ama, sendo que o despertar de tais sentimentos tem grande probabilidade de motivá-lo na busca de novas relações.

- Uma das alternativas atuais é a participação em grupos de terceira idade, uma vez que estes oportunizam novas possibilidades e perspectivas de vida. É de fundamental importância, para o bem viver da população idosa, incentivar que as pessoas, na velhice, busquem manter boas expectativas para a vida com planejamento e crença no futuro, como salienta a autora:

...as pessoas de mais idade dentro de um
grupo sociocultural podem afirmar a sua
própria identidade, expandir as fronteiras
de seu valor, reconhecerem-se como
participantes da vida atual do grupo, por
meio da memória compartilhada, porque
a identidade individual é uma instância
que depende do outro. (Neri, 2001, p. 144)

O envelhecimento, que vem sendo cada dia mais estudado, tem contribuído para que a sociedade possa repensar a visão preconceituosa que, historicamente, tem mostrado em relação a essa faixa etária. Idoso saudável hoje já está sendo uma realidade mais presente em nossa sociedade, pois a procura de estimulação como forma de manutenção funcional de suas habilidades e a disposição para a descoberta de novos aprendizados têm aberto novas perspectivas em relação à vivência do idoso. Para enfatizar essa afirmação, Zimerman (2000) afirma que:

\footnotetext{
As pessoas mais saudáveis e mais otimistas têm condições de se adaptarem às transformações trazidas pelo envelhecimento. Elas estão mais propensas a verem a velhice como um tempo de experiências acumuladas, de maturidade, de liberdade para assumir novas ocupações e, até mesmo, de liberação de certas responsabilidades. (p. 25)
}

- A manifestação de religiosidade é considerada como uma forma positiva de enfrentamento do estresse, como menciona Neri (2001).

Aristóteles e Cícero (como citado por Monteiro, 2002, p. 2) já salientavam que “...a felicidade na velhice é fruto de uma vida virtuosa, em 
que o senso de realização pessoal é produto do senso de viver sempre em busca de um ideal de excelência pessoal". Tais afirmações reforçam o que os atuais estudos vêm indicando em relação à qualidade de vida do idoso.

A gerontologia, como uma ciência que se propõe estudar as particularidades do envelhecimento, tem contribuído sobremaneira tanto para o melhor entendimento desse processo bem como dos determinantes biopsicossociais. Seu caráter científico multi e interdisciplinar se constitui em um elo de ligação entre diferentes disciplinas, mas que tem como objetivo comum o estudo dos múltiplos aspectos do fenômeno do envelhecimento (Freitas et al., 2002).

A personalidade não muda com o envelhecimento, mas proporciona maior interiorização do self, pela qual a pessoa adquire o senso de ser única, passando, portanto, a um processo, de acordo com Jung, (como citado por Freitas et al., 2002) chamado de individuação, que é definido como

...um embate espiritual e cultural típico dos anos da meia-idade e da velhice. Inclui o desvelar dos aspectos menos educados e mais reprimidos do self (a 'sombra') e a descoberta das próprias possibilidades de aquisição de novos papéis, de planejamento de novas metas e de contribuição para a sociedade (a "persona"). (Citado por Freitas et al., 2002, p. 35)

A atividade, ao longo da vida, está sempre baseada em metas, projetos de vida e tentativas de executá-los com sucesso. $\mathrm{Na}$ velhice, a realidade não poderia ser outra; no entanto, os projetos de vida podem ser constantemente revistos e adaptados para que se logre êxito. Ao idoso, cabe a responsabilidade de continuar planejando e desejando, dentro de suas condições de vida.
Metodologia de atuação grupal

O primeiro grupo desenvolvido foi o grupo Cuidando do Cuidador, que tinha como premissa básica a grande dificuldade encontrada pela família e/ou cuidadores na atuação com idosos dependentes e semidependentes, tornando-se necessário ter um olhar mais atento em relação às pessoas que tem essa árdua função de cuidadores. Portanto, atentar para os sentimentos de angústia, ansiedade, tristeza, solidão, cansaço, dentre outros aspectos percebidos em tais familiares que desempenham a função de cuidadores, muitas vezes abrindo mão de suas próprias vidas, despertou meu interesse na implementação desse grupo.

Esse grupo tinha como objetivo principal proporcionar um momento de reflexão quanto ao cuidar e ser cuidado para os familiares e/ ou acompanhantes que desempenham a função de cuidadores bem como dar a oportunidade de atentar para os sentimentos negativos e positivos em relação às atividades desempenhadas como cuidadores; favorecer o despertar da necessidade de preservar seus momentos pessoais de atividades prazerosas; contribuir para melhor conscientização do cuidador do idoso, diante das necessidades e dificuldades dessa clientela; informar e esclarecer os aspectos do envelhecimento e sua relação com o comportamento limitante do idoso e contribuir para um atendimento humanizado do idoso.

A metodologia foi baseada no uso de recursos didáticos que proporcionam a reflexão dos conteúdos emergentes que norteiam o cotidiano da família/cuidador, tais como: técnicas de dinâmica dos grupos, sensibilização, dramatização, vídeos, músicas, pinturas, desenhos, colagens e danças, dentre outros. Tais grupos foram coordenados, de 
forma integrada, pelo serviço de psicologia e pela médica homeopata.

O grupo era composto de familiares/ cuidadores de ambos os sexos, escolhidos conforme a demanda entre os próprios idosos do programa que desempenhavam o papel de cuidadores e dos familiares-cuidadores dos idosos atendidos pela instituição. O grupo foi formado por 10 participantes mulheres, sendo três idosas cuidadoras de seus maridos e sete familiares que cuidavam de idosos atendidos pela instituição.

Os encontros aconteciam semanalmente, com duas horas de duração cada, durante quatro meses, sendo realizada, inicialmente, uma atividade corporal de dança, relaxamento ou alongamento. Em seguida, um tema era discutido, através do uso de algum recurso facilitador das discussões, tais como técnicas de dinâmica dos grupos e/ou de algum texto, ocasião em que o grupo tinha um momento para reflexão e outro para a partilha da experiência vivenciada. No encerramento, freqüentemente, realizava-se uma atividade de integração e acolhimento.

Os relatos dos participantes refletiram uma avaliação positiva dos encontros, pois mostravam-se mais continentes e tranqüilos em relação à difícil e árdua jornada diária que enfrentavam no cuidar. Um aspecto relevante que se pode observar foi que estes despertaram para a importância de também serem merecedores de cuidado e atenção, passando então a dedicar algum tempo a si mesmos e a descentralizar a responsabilidade do cuidar para outras pessoas que, até então, se mostravam desobrigadas de participar, direta ou indiretamente, dessa demanda. Esse grupo teve a duração de quatro meses e, apesar dos resultados positivos alcançados, foi interrompido; no entanto, pretende-se futuramente formar novos grupos.

Outro grupo desenvolvido foi o Exercitando o Corpo e a Mente, pois a população idosa atendida pelo Centro de Atenção à Saúde do Idoso freqüentemente, tinha, em suas atividades cotidianas, a participação em grupos que oportunizam o relacionamento inter e intrapessoal e o aprendizado de práticas antiestresse, que favorecem melhor qualidade de vida. Partindo-se desse princípio, foi criado o grupo utilizando como metodologia o "Lian Gong". O método Lian Gong, realizado em 18 terapias, é uma técnica que une a Medicina Terapêutica Chinesa (MTC) e a cultura física. É considerada uma "ginástica de arteterapia e de prevenção de síndromes de dores no pescoço, nos ombros, na região lombar, nas pernas e nas articulações das extremidades" (Ming, 2000, p. 27).

O Lian Gong compõe-se de duas partes: a primeira trata de desequilíbrios e dores no corpo e previne o seu aparecimento; a segunda trata as tenossinovites e disfunções dos órgãos internos assim como as dores nas extremidades das articulações, prevenindo igualmente o aparecimento dessas disfunções. A execução do Lian Gong, com a realização dos 18 exercícios que compõem a série, tem a duração de 12 minutos. Os exercícios são simples, acessíveis a pessoas de todas as idades. Segundo Ming, "na terceira idade, a prática do Lian Gong em 18 terapias ajuda a recuperar e preservar o estado fisiológico do corpo fortalecendo os membros e as funções dos órgãos e retardando o envelhecimento" (Ming, 2000, p. 30).

Lian Gong caracteriza-se pelo trabalho persistente e prolongado de treinar e exercitar o corpo físico, com o objetivo de transformálo de fraco em forte e de doente em saudável. No entanto, optei por elaborar um grupo que pudesse não só buscar os benefícios proporcionados por essa prática corporal mas também que não tivesse o caráter de somente formar praticantes, para que os idosos tivessem a oportunidade de perceber a importância de práticas corporais de prevenção e promoção de saúde e as 
utilizassem como algo freqüente em seu cotidiano. A partir de então, desenvolveu-se um grupo dinâmico com técnicas variadas que promoviam momentos de descontração, aliados à responsabilidade do autocuidado com a saúde.

O objetivo prioritário dessa intervenção era proporcionar ao idoso a descoberta de práticas corporais saudáveis de prevenção e promoção de saúde, mas também objetivava informar e esclarecer os aspectos do envelhecimento e sua relação com a necessidade do comportamento de autocuidado do idoso, despertar no idoso a necessidade de buscar qualidade de vida, incentivar a prática rotineira de exercícios corporais que proporcionassem melhora da respiração, fortalecer o sistema cardiorespiratório e o aparelho locomotor e contribuir para a melhoria e a manutenção da saúde e da funcionalidade do idoso. A técnica usada foi baseada em atividades que proporcionam estímulo físico e mental aos idosos bem como oportunizam o aprendizado de práticas corporais saudáveis de prevenção e promoção de saúde.

A prática do Lian Gong foi constante nos encontros, bem como a realização de dança, relaxamento, alongamento e variadas técnicas que possibilitassem aos idosos um encontro harmonioso consigo mesmos, com os outros e com a natureza. O grupo foi coordenado pela psicóloga, pela médica homeopata e pela terapeuta ocupacional. O número de participantes formou-se a partir da demanda apresentada pelos idosos, ressaltando-se que o grupo era aberto, a fim de levar essa prática corporal ao maior número possível de usuários.

Vale ressaltar que o critério de seleção dos participantes foi sua disposição e interesse em participar do grupo. Os encontros foram realizados semanalmente, com duas horas e trinta minutos de duração, por quatro meses, de agosto a dezembro de 2006.
Os relatos dos participantes indicam os benefícios das atividades corporais, que proporcionam vitalidade no processo do envelhecimento. Os idosos, em seus relatos, informam que passaram a perceber que ser um idoso saudável não era tão difícil quanto imaginavam, pois começaram a ampliar suas redes de relações sociais e viram a necessidade da cooperação mútua, realizada de maneira descontraída e alegre, na busca da saúde. Descobriram a importância de serem os responsáveis pela própria saúde, pois aprenderam a conhecer o corpo, e, em conseqüência, identificaram suas limitações e potencialidades. O autocuidado apareceu como um dos mais importantes ganhos para esses idosos. O grupo durou seis meses, verificando-se a necessidade de continuidade, uma vez que os resultados obtidos contribuíram bastante para a saúde mental, emocional e social dos idosos.

O grupo de apoio Cuidando da Saúde com Alegria foi implementado como um grupo de atendimento do idoso com caráter de apoio, onde este teria condições de encontrar um espaço de informação, reflexão e, fundamentalmente, apoio, diante das necessidades que possuem nessa fase, tais como conflitos familiares, adoecimento, discriminação, preconceitos e perdas, dentre outros.

O grupo de apoio foi baseado, principalmente, na busca de estratégias lúdicas que proporcionassem atividades divertidas e alegres, pois entende-se que o idoso pode e deve ser responsável por sua saúde, mas precisa de estímulo e ajuda para perceber e conscientizar-se dessa necessidade de uma forma satisfatoriamente estimulante. Conscientizar o idoso da importância e da necessidade de responsabilizar-se pelo cuidado com a sua saúde, através de estratégias lúdicas que despertem alegria e diversão, foi o objetivo principal dessa intervenção; no entanto, buscou-se também 
informar e esclarecer os aspectos do envelhecimento, favorecer a necessidade do autocuidado do idoso, contribuir para melhor conscientização do idoso diante das necessidades, dificuldades e limitações que possuem nessa fase e, finalmente, despertálo para a necessidade de proporcionar e preservar momentos de atividades pessoais prazerosas em seu dia a dia.

A metodologia foi baseada no uso de recursos lúdicos, que facilitavam a expressão de sentimentos e pensamentos emergentes dos idosos, através de estratégias que proporcionavam reflexão, mas foi percebida a importância de essas atividades também terem caráter de diversão e alegria. Dentre os recursos usados, estavam: dramatizações, vídeos, músicas, pinturas, desenho, colagens, danças circulares, canto e oficinas temáticas.

Esses grupos foram coordenados, de forma integrada, pelo serviço de psicologia e pela médica homeopata. O grupo era composto por 20 idosos, encaminhados a participar do grupo pela equipe de saúde. Os encontros eram realizados semanalmente, com duas horas de duração cada. O grupo teve a duração de seis meses.

Pôde-se perceber, com o decorrer dos encontros, que os participantes relataram maior satisfação com a vida, declarando que a participação nos grupos havia mudado a maneira como percebiam a realidade em que viviam e que haviam começado a encontrar pontos positivos em seu cotidiano e a valorizá-los. Informaram que a motivação para participarem das atividades havia aumentado, e que haviam despertado para a importância de cuidarem da saúde e não "cultivarem" doenças e sentimentos negativos. Portanto, o desenvolvimento de tal projeto contribuiu grandemente para o crescimento pessoal do idoso como agente ativo na busca de sua saúde.

\section{Considerações finais}

A partir dessa nova concepção de envelhecimento como uma fase com muitas possibilidades de aprendizagem e conhecimento, torna-se necessário buscar estratégias para facilitar ao idoso o enfrentamento desse processo e a ruptura com a visão passiva da velhice.

Essa experiência objetivou despertar nos profissionais de saúde o interesse e a disposição em cuidar, com mais respeito e dedicação, da população idosa, não só pelo fenômeno do crescimento acelerado que esse segmento etário vem tendo em nosso país mas também para contribuir na busca do auto-cuidado, da qualidade de vida do idoso e do enfrentamento do processo de envelhecimento. Nesse sentido, o papel da equipe multi e interdisciplinar nos programas de atenção à saúde do idoso é essencial, pois, além do acesso a condições de saúde adequadas, proporciona o atendimento integral às necessidades dos idosos, incentivando a manutenção de uma vida saudável, com atividades prazerosas, alternativas e motivadoras e sem restringir-se à questão medicamentosa e patológica.

A atividade, ao longo da vida, está baseada em metas e projetos de vida, e, no processo de envelhecimento, faz-se necessário revê-los e adaptá-los para alcançar êxito. Ao idoso, cabe a responsabilidade de continuar utilizando sua experiência de vida no convívio com as patologias dessa fase, elaborando perdas e ganhos, e, simultaneamente, planejando e desejando dentro de seu processo de envelhecimento.

É importante destacar o papel do psicólogo como facilitador do processo grupal, pois ele possibilita a socialização e a revisão das experiências em comum, que precisam ser mantidas e/ou resgatadas. Portanto, a formação de grupos de idosos torna-se uma alternativa 
bastante viável na promoção e na prevenção da saúde biopsicossocial dos idosos no serviço público, e constitui uma experiência enriquecedora, que proporciona a formação de uma rede de suporte psicossocial entre os participantes enquanto modalidade de intervenção psicológica que contribui tanto para a valorização da identidade como para o reconhecimento da alteridade pelo idoso.

Dessa forma, as atividades com grupos de idosos devem ser utilizadas no cotidiano da psicogerontologia como recurso de atendimento, visto que oportunizam novas perspectivas de vida, a expansão das fronteiras de seu valor pessoal, a manutenção de atividades prazerosas e o planejamento de projetos de vida e crença no futuro, o que possibilita a aquisição e/ou manutenção de estratégias para o enfrentamento do processo de envelhecimento. 
Falcão, D. V. S., \& Dias, C. M. S. B. (2006). Maturidade e velhice: pesquisas e intervenções psicológicas. São Paulo: Casa do Psicólogo.

Freitas et al. (2002). Tratado de geriatria e gerontologia. Rio de Janeiro: Guanabara Koogan.

Ming, Z.Y. (2000). Lian gong shi ba fa (lian gong em 18 terapias). São Paulo: Pensamento.

Monteiro, D. (2002). Depressão e envelhecimento: saídas criativas. Rio de Janeiro: Revinter.
Neri, A. L. (2001). Desenvolvimento e envelhecimento: perspectivas biológicas, psicológicas e sociológicas. Campinas, SP: Papirus.

Papaléo Netto, M. (2005). Gerontologia: a velhice e o envelhecimento em visão globalizada. São Paulo: Atheneu.

Stuart-Hamilton, I. (2002). A psicologia do envelhecimento: uma introdução. Porto Alegre: Artmed.

Zimerman, G. I. (2000). Velhice: aspectos biopsicossociais. Porto Alegre: Artes Médicas Sul. 